\section{Recreational football is effective in the treatment of non-communicable diseases}

\author{
Peter Krustrup, ${ }^{1,2}$ Jens Bangsbo ${ }^{1}$
}

A decade ago, it was established that physical activity is a cornerstone in the nonpharmacological prevention and treatment of non-communicable diseases, ${ }^{1}$ and there is increasing evidence that sports participation has the potential to improve the health of nations. ${ }^{2}$ In recent years, more than 60 scientific articles have shown that recreational football training conducted as small-sided games ( $3 \mathrm{v} 3$ to $7 \mathrm{v} 7)$ has substantial fitness and health benefits for untrained individuals. $^{3-6}$ Such easy-to-do training has resulted in reduced blood pressure and resting heart rate, reduced fat mass and lipid profile, and favourably changed cardiac function and size, muscle mass, bone mineralisation and functional capacity. This applied for participants across the lifespan-irrespective of gender, social status and prior football experience.

\section{BEST EVIDENCE FOR FOOTBALL AND RUNNING}

Among healthy individuals, the effects of recreational football training are more broad-spectred (more systems benefitted) and more pronounced than training modalities such as cycling, swimming, jogging, walking and strength training, suggesting that football may be a more powerful stimulus for health. ${ }^{35} 7$ A very recent systematic review on the health benefits of different sport disciplines for adults, published last month in BJSM, led Oja et $a l^{7}$ to conclude that: "Best evidence was found for football and running. These can especially improve cardiovascular and metabolic health"?

\section{THE POWER OF FOOTBALL FOR PATIENTS WITH NON-COMMUNICABLE DISEASES (NCDS)}

It is both important and remarkable that for patients with non-communicable

\footnotetext{
${ }^{1}$ Department of Nutrition, Exercise and Sports, Copenhagen Centre for Team Sport and Health, University of Copenhagen, Copenhagen, Denmark; ${ }^{2}$ Sport and Health Sciences, College of Life and Enviromental Sciences, University of Exeter, Exeter, UK Correspondence to Professor Jens Bangsbo, Department of Nutrition, Exercise and Sports, Copenhagen Centre for Team Sport and Health, University of Copenhagen, Copenhagen $\varnothing 2100$, Denmark; jbangsbo@nexs.ku.dk
}

diseases (NCDs), such as hypertension and type 2 diabetes mellitus (T2DM), the benefits of football are even greater on key clinical measures than they are in the healthier cohort. Thus, twice-weekly football sessions over 24 weeks for men with hypertension led to a 151-to- $139 \mathrm{~mm} \mathrm{Hg}$ drop in systolic blood pressure and a 92to- $84 \mathrm{~mm} \mathrm{Hg}$ decrease in diastolic blood pressure $^{4}$ with three-quarters of the football group participants no longer hypertensive after the study. Likewise, just 12-15 weeks of football training lowered blood pressure by $12 / 6$ and $8 / 7 \mathrm{~mm} \mathrm{Hg}$, respectively, for hypertensive women and men with type 2 diabetes. ${ }^{5}$ Such blood pressure reductions are more pronounced than those reported for other exercise interventions with hypertensive and patients with T2DM, and similar to or greater than the effects of medication. ${ }^{1}$

Along with marked improvements in cardiac function and cardiorespiratory fitness, the blood pressure reductions are likely to reduce patients' high risk of cardiovascular diseases. In T2DM men, total and android fat mass was lowered by $1.7 \mathrm{~kg}$ and 13\%, respectively, after 24 weeks of football training, and men and women aged 48-68 years with TDM2 lost $3.4 \mathrm{~kg}$ of fat, and achieved concomitant reductions in plasma lowdensity lipoprotein cholesterol and triglycerides by combining 12 weeks of football with a calorie-reduced diet. ${ }^{5}$ Moreover, the hypertensive and patients with T2DM experienced improved functional capacity, had $10-12 \%$ increases in maximum oxygen uptake and marked effects on body composition after 12-24 weeks of football training. ${ }^{4-6}$ Another prominent example of the power of football for patients is that elderly men with prostate cancer in androgen deprivation therapy had elevated muscle strength (15\%), sit-to-stand performance $(8 \%)$ and muscle mass $(0.7 \mathrm{~kg})$ after 12 weeks of training. ${ }^{5}$

\section{INTRINSIC MOTIVATION, SOCIAL INTERACTION AND LOW PERCEIVED EXERTION}

People with NCDs are often not very active and are recommended to increase their level of physical activity. Some patients initiate endurance training or fitness centre training after being diagnosed, but many stop after a short period due to motivational problems. Thus, a significant challenge is to maintain a keen interest in physical activity. A significant finding in all the studies involving recreational football and other team sports is that the participants enjoyed themselves when playing. ${ }^{5}$ During football training, average heart rates are above $80 \%$ of maximal heart rate also in patients with hypertension, T2DM and prostate cancer. $^{5} 6$ Importantly, despite the high heart rates during training, recreational football training had lower scores in perceived exertion in comparison with other activities, such as jogging, interval running and fitness training. ${ }^{3}$ Combined with positive social interaction and internal motivation, this may explain why participants adhere to training after ending the recreational football intervention studies. ${ }^{5}$

\section{WIDE IMPLICATIONS-PUBLIC HEALTH POLICY}

These data should not be ignored by health policymakers around the globe. ${ }^{8}$ Recreational football is an effective, social and joyful, all-in-one type of training that can be used as a broad-spectrum nonpharmacological treatment for NCDs. Today, more than 400 million people regularly play football, and FIFA president Joseph Blatter and F-MARC chair Jiri Dvorak recently stated that football shows "great promise in changing the habits of untrained people all over the world, creating adherence to a physically active and healthier lifestyle". 8

FIFA plays a very active role in the implementation and promotion of Football for Health, but it also requires a considerable collaborative effort from governmental authorities, football federations and practitioners to make use of the information. These issues will be addressed at the 8th World Congress on Science and Football on 20-23 May 2015, in Copenhagen, where new results will be presented along with the new Danish concept of 'Football Fitness' for sedentary adults and FIFA's strategy for implementing 'FIFA 11 for Health', for school children in 100 countries.

Acknowledgements The authors thank the team at the Copenhagen Centre for Team Sport and Health, University of Copenhagen, supported by Nordeafonden, Denmark, as well as close collaborators in 12 countries.

Competing interests None declared. 
Patient consent Obtained.

Ethics approval Regional Ethics Committee.

Provenance and peer review Not commissioned; internally peer reviewed.

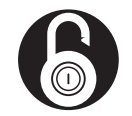

OPEN ACCESS

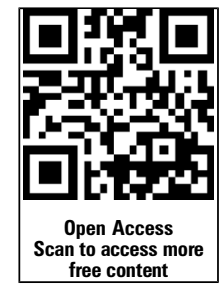

Open Access This is an Open Access article distributed in accordance with the Creative Commons Attribution Non Commercial (CC BY-NC 4.0) license, which permits others to distribute, remix, adapt, build upon this work non-commercially, and license their derivative works on different terms, provided the original work is properly cited and the use is noncommercial. See: http://creativecommons.org/licenses/ by-nc/4.0/
4 Krustrup P, Randers MB, Andersen LJ, et al. Soccer improves fitness and attenuates cardiovascular risk factors in hypertensive men. Med Sci Sports Exerc 2013:45:553-60.

5 Bangsbo J, Junge A, Dvorak J, et al. Executive summary: football for health—prevention and treatment of non-communicable diseases across the lifespan through football. Scand I Med Sci Sports 2014;24(Suppl 1):147-50.

6 Bangsbo J, Hansen PR, Dvorak J, et al. Recreational football for disease prevention and treatment in untrained men: a narrative review examining cardiovascular health, lipid profile, body composition, muscle strength and functional capacity. $\mathrm{Br} /$ Sports Med 2015;49:568-76

\section{REFERENCES}

1 Pedersen BK, Saltin B. Evidence for prescribing exercise as therapy in chronic disease. Scand I Med Sci Sports 2006;16(Suppl 1):3-63.

2 Khan KM, Thompson AM, Blair SN, et al. Sport and exercise as contributors to the health of nations. Lancet 2012;380:59-64.

3 Krustrup P, Aagaard P, Nybo L, et al. Recreational football as a health promoting activity: a topical review. Scand J Med Sci Sports 2010;20(Suppl 1):1-13. 